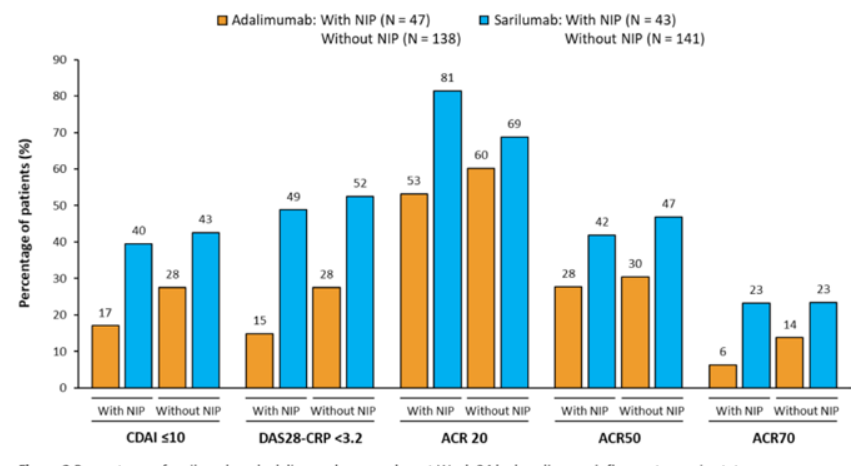

Figure 2 Percentages of sarilumab and adalimumab responders at Week 24 by baseline noninflammatory pain status

24 when treated with sarilumab versus placebo or adalimumab. Patients with and without BL NIP had greater improvements in pain when treated with sarilumab versus adalimumab. The difference in clinical improvement was greater among patients with BL NIP versus without BL NIP for most measures. These trends support the emerging concept that mechanisms other than direct inflammation may contribute to pain in RA, potentially mediated via IL-6 signaling.

References:

[1] Durán J et al. Rheumatology. 2015;54:2166-70

[2] Pollard LC et al. Rheumatology. 2010;49:924-8

Acknowledgments: Study funding and medical writing support (Joseph Hodgson, PhD, Adelphi Communications Ltd, Macclesfield, UK) provided by Sanofi Genzyme (Cambridge, MA, USA) and Regeneron Pharmaceuticals, Inc. (Tarrytown, NJ, USA) in accordance with GPP3 guidelines.

Disclosure of Interests: Ernest Choy Grant/research support from: Amgen, Bio-Cancer, Chugai Pharma, Ferring Pharmaceuticals, Novimmune, Pfizer, Roche, UCB, Consultant of: AbbVie, Amgen, AstraZeneca, Biogen, Boehringer Ingelheim, Bristol-Myers Squibb, Celgene, Chelsea Therapeutics, Chugai Pharma, Daiichi Sankyo, Eli Lilly, Ferring Pharmaceuticals, GlaxoSmithKline, Hospita, Ionis, Janssen, Jazz Pharmaceuticals, Medlmmune, Merck Sharp \& Dohme, Merrimack Pharmaceutical, Napp, Novartis, Novimmune, ObsEva, Pfizer, R-Pharm, Regeneron Pharmaceuticals, Inc., Roche, SynAct Pharma, Sanofi Genzyme, Tonix, UCB, Speakers bureau: Amgen, Boehringer Ingelheim, Bristol-Myers Squibb, Chugai Pharma, Eli Lilly, Hospira, Merck Sharp \& Dohme, Novartis, Pfizer, Regeneron Pharmaceuticals, Inc., Roche, Sanofi-Aventis, UCB, Vivian Bykerk: None declared, Yvonne Lee Shareholder of: Cigna-Express Scripts, Grant/research support from: Pfizer, Consultant of: Highland Instruments, Inc., Gregory St John Shareholder of: Regeneron Pharmaceuticals, Inc., Employee of: Regeneron Pharmaceuticals, Inc., Hubert van Hoogstraten Shareholder of: Sanofi, Employee of: Sanofi, Kerri Ford Shareholder of: Sanofi Genzyme, Employee of: Sanofi Genzyme, Amy Praestgaard Employee of: Sanofi Genzyme, Anthony Sebba Consultant of: Genentech, Gilead, Lilly, Regeneron Pharmaceuticals Inc., Sanofi, Speakers bureau: Lilly, Roche, Sanofi

DOI: 10.1136/annrheumdis-2020-eular.2015

\section{SAT0103 \\ THE EFFECT OF BODYWEIGHT ON RESPONSE TO INTRAVENOUS OR SUBCUTANEOUS TOCILIZUMAB IN PATIENTS WITH RHEUMATOID ARTHRITIS}

R. Davies ${ }^{1}$, A. Vivekanantham ${ }^{2}$, M. Lunt ${ }^{1}$, K. Watson ${ }^{1}$, K. Hyrich ${ }^{1,3}$, J. Bluett ${ }^{3,4}$ on behalf of BSRBR-RA Contributors Group. ${ }^{1}$ University of Manchester, Centre for Epidemiology Versus Arthritis, Manchester, United Kingdom; ${ }^{2}$ University of Manchester, Centre for Epidemiology Versus Arthritis, Manchester, United Kingdom; ${ }^{3}$ Manchester Academic Health Science, National Institute of Health Research Musculoskeletal Biomedical Research Centre, Manchester, United Kingdom; ${ }^{4}$ University of Manchester, Versus Arthritis Centre for Genetics and Genomics, Manchester, United Kingdom

Background: Tocilizumab is an IL-6 receptor humanised monoclonal antibody treatment option in rheumatoid arthritis (RA) who have not responded or are intolerant of disease modifying anti-rheumatic drugs (DMARDs) or other biologics. Tocilizumab was available initially as an intravenous (IV) preparation, dosed according to weight, and more recently as a subcutaneous (SC) preparation given at $162 \mathrm{mg} /$ weekly irrespective of bodyweight.

Obesity is highly prevalent in RA and there has been concern that starting or switching patients to SC tocilizumab could reduce its effectiveness in those patients with a higher body weight when compared to IV tocilizumab.

Objectives: To investigate the relationship between bodyweight and DAS28 response at 6 months in tocilizumab naïve RA patients starting IV or SC tocilizumab. Methods: The study population comprised RA subjects recruited to the BSRBR-RA up to $30 / 11 / 2018$ commencing IV or SC tocilizumab for the first time. Patients had to be tocilizumab naïve and have at least one six monthly study follow-up recorded after starting tocilizumab. Baseline characteristics at point of starting tocilizumab are described. Linear regression, fully adjusted for relevant confounders, was used to investigate the relationship between change in DAS28 score from baseline to six months and body weight per ten kilograms ( $\mathrm{kg}$ ), and in a separate analysis, as BMI category. Multiple imputation was used to handle missing data.

Results: 1241 patients starting tocilizumab (902 IV, 339 SC) were eligible for analysis. The median age was 59 years, majority were female, and had median disease duration of 11 years at baseline. Over seventy percent had prior biologic exposure. Median weight was $77 \mathrm{~kg}$ for IV and $76 \mathrm{~kg}$ for SC starters, and the majority of patients were categorised as normal weight $(30 \% \mathrm{IV}, 37 \% \mathrm{SC})$ or pre-obesity ( $31 \%$ IV \& SC) according to BMI. Median DAS28 score was 5.8 (IV) and 5.5 (SC) at start of treatment with median improvement after 6-months of 1.50 and 2.02 units respectively. The fully adjusted linear regression model showed no association between body weight or BMI and change in DAS28 score at six months for patients starting IV or SC tocilizumab. (Table).

\section{Table}

\begin{tabular}{|c|c|c|}
\hline Baseline Variable & $\begin{array}{l}\text { Intravenous TCZ patients } \\
\qquad(\mathrm{n}=902)\end{array}$ & $\begin{array}{l}\text { Subcutaneous } \\
\text { TCZ patients } \\
(n=339)\end{array}$ \\
\hline Age, median (IQR) & $58(50-67)$ & $60(51-70)$ \\
\hline Gender, n (\%) female & $708(78)$ & $233(74)$ \\
\hline $\begin{array}{l}\text { Disease duration, median (IQR) } \\
\text { years }\end{array}$ & $11(4-21)$ & $11(4-21)$ \\
\hline DAS28 score, median (IQR) & $5.8(5.1-6.6)$ & $5.5(4.7-6.5)$ \\
\hline $\begin{array}{l}\text { Change in DAS28 score, median } \\
\text { (IQR) }\end{array}$ & $-1.50(-3.10--0.23)$ & $-2.02(-3.72--0.37)$ \\
\hline Weight in KGs, median (IQR) & $77(64-91)$ & $\begin{array}{c}76(64-88) \\
\text { Change in DAS28, } \\
\text { coefficient (95\% } \\
\text { Cl) }\end{array}$ \\
\hline $\begin{array}{l}\text { Body weight per } 10 \mathrm{kgs}^{*} \\
\text { BMI category* }^{*}\end{array}$ & $0.04(-0.01-0.09)$ & $-0.005(-0.11-0.10)$ \\
\hline Normal weight & ref & ref \\
\hline Underweight & $-0.41(-1.27-0.46)$ & $0.08(-1.62-1.77)$ \\
\hline Pre-obesity & $-0.26(-0.57-0.05)$ & $0.02(-0.44-0.48)$ \\
\hline Obesity class I, II \& III & $-0.03(-0.35-0.29)$ & $0.08(-0.40-0.55)$ \\
\hline
\end{tabular}

${ }^{*}$ Fully adjusted for age, gender, disease duration, baseline DAS28 score, baseline HAQ score co-morbidities, and number of previous biologics

Conclusion: Data from this study show that body weight does not appear to affect initial response to IV or SC tocilizumab. This is reassuring given that patients are likely to be given SC tocilizumab due to ease of administration and reduced hospital costs.

Disclosure of Interests: Rebecca Davies: None declared, Arani Vivekanantham: None declared, Mark Lunt: None declared, Kath Watson: None declared, Kimme Hyrich Grant/research support from: Pfizer, UCB, BMS, Speakers bureau: Abbvie, James Bluett: None declared

DOI: 10.1136/annrheumdis-2020-eular.4164

\section{SAT0104 MAINTENANCE OF SDAI REMISSION AND PATIENT- REPORTED OUTCOMES (PROS) FOLLOWING DOSE DE-ESCALATION OF ABATACEPT IN MTX-NAÏVE, ANTI-CITRULLINATED PROTEIN ANTIBODY (ACPA)+ PATIENTS WITH EARLY RA: RESULTS FROM AVERT-2, A RANDOMISED PHASE IIIB STUDY}

P. Emery ${ }^{1}$, Y. Tanaka ${ }^{2}$, V. Bykerk ${ }^{3}$, T. Huizinga ${ }^{4}$, G. Citera ${ }^{5}$, C. Bingham ${ }^{6}$, S. Banerjee ${ }^{7}$, S. Connolly ${ }^{7}$, J. Zhuo ${ }^{7}$, R. Wong ${ }^{7}$, K. H. G. Huang ${ }^{7}$, K. Lozenski ${ }^{7}$, Y. Elbez ${ }^{8}$, R. Fleischmann.${ }^{1}$ LIRMM, University of Leeds, NIHR BRC LTHT, Leeds, United Kingdom; ${ }^{2}$ University of Occupational and Environmental Health, Kitakyushu City, Japan; ${ }^{3}$ Hospital for Special Surgery, New York, United States of America; ${ }^{4}$ Leiden University Medical Center, Leiden, Netherlands; ${ }^{5}$ Instituto de Rehabilitacion Psicofisca, Buenos Aires, Argentina; ${ }^{6} J o h n s$ Hopkins University, Baltimore, United States of America; ${ }^{7}$ Bristol-Myers Squibb, Princeton, United States of America; ${ }^{8}$ Excelya, Boulogne-Billancourt, France; ${ }^{9}$ University of Texas, Dallas, United States of America

Background: The Phase Illb Assessing Very Early RA Treatment (AVERT)-2 trial (NCT02504268) evaluated SC abatacept (ABA) + MTX vs ABA placebo (PBO) + MTX in ACPA+ patients (pts) with early, active RA. ${ }^{1}$ Results from the 56-wk induction period (IP) showed a significantly greater proportion of pts treated with $A B A$ + MTX (vs MTX alone) reported clinically meaningful improvements in HAQ-DI, global disease activity and pain, which were sustained at $52 \mathrm{wks}^{2}$

Objectives: To report maintenance of SDAI remission and PROs from the AVERT-2 de-escalation (D-E) period. 